\title{
Crystal Structure and DFT Calculation Studies of Ni (II) Cinnamaldehyde Thiosemicarbazone Complex
}

\author{
Karima Benhamed ${ }^{1}$, Leila Boukli-Hacene ${ }^{1, *}$ and Yahia Harek ${ }^{2}$ \\ ${ }^{1}$ Laboratoire de Chimie Inorganique et Environnement, BP 119, Université de Tlemcen, Algeria \\ ${ }^{2}$ Laboratoire de Chimie Analytique et Electrochimie, BP 119, Université de Tlemcen, Algeria
}

\begin{abstract}
Slow evaporation of a dilute DMSO solution of the title compound at room temperature, provided a brown crystal of $\mathrm{Ni}(\mathrm{CMTSC})_{2} \mathrm{DMSO}$ suitable for X-Rays study (space group: $\mathrm{P}-1, \mathrm{a}(\AA)=8.1750(3)$, $\left.\mathrm{b}(\AA)=11.3400(4), \mathrm{c}(\AA)=15.1940(5), \alpha\left(^{\circ}\right)=68.581(3), \beta\left(^{\circ}\right)=78.894(4), \gamma\left({ }^{\circ}\right)=79.265(5)\right)$. Two Ni atoms were located on special positions providing two molecules of $\mathrm{Ni}(\mathrm{CMTSC})_{2}$ different for their torsion angles and intermolecular interactions. In both molecules, the thiosemicarbazone coordinates as an anionic ligand via the thiosemicarbazone moiety's azomethine nitrogen and thiolatosulphur in a square-planar geometry. In the aim of investigating structural features, Density Functional Theory calculations of both ligand and complex were fully optimised with respect to the energy using B3LYP level. The predicted geometry parameters are compared with their corresponding X-ray crystallographic data.
\end{abstract}

Keywords: Ni(II) complex; thiosemicarbazone; cinnamaldehyde; DFT calculations; crystal structure.

\section{Introduction}

Thiosemicarbazones (TSCs) constantly attract the interest of chemist and pharmacist because of their well-known and remarkable biological and pharmacological properties (antiviral, antibacterial or antitumoral activities); that is why the literature concerning these subjects is steadily increasing ${ }^{1-5}$. Such pharmacological activities are due to the strong chelating ability of these ligands with biologically important metal ions such as $\mathrm{Fe}^{2+}, \mathrm{Cu}^{2+}, \mathrm{Ni}^{2+}$ and their reductive capacities ${ }^{6,7}$.

However, not only the bioinorganic relevance of the complexes but also the chemistry of transition metal complexes of the thiosemicarbazones is receiving significant current attention because of the variable binding modes displayed by these ligands in their complexes ${ }^{8-14}$. Thiosemicarbazones usually bind to a metal ion as bidentate $\mathrm{N}, \mathrm{S}$ donor ligands via dissociation of the hydrazinic proton, forming five-membered chelate rings. Because the ligands can bind either as the neutral species or monodeprotonated, crystallographically the difference can generally be monitored by the length of the $\mathrm{C}-\mathrm{S}$ bond. The neutral ligand contains a formal $\mathrm{C}-\mathrm{S}$ double bond with bond lengths of the order of $1.67-1.72 \AA$, while the deprotonated ligand undergoes tautomerization to produce a formal $\mathrm{C}-\mathrm{S}$ single bond with bond lengths of the order of $1.71-1.80 \AA^{15}$.
In some cases TSC can act as a C, N, S donor, forming cyclometallated complexes ${ }^{16,17}$. An overview of thiosemicarbazone complexes was published by Lobana and al. ${ }^{18}$. The presence of multiple donor atoms within the same ligand multiplying coordination modes affects the properties of ligands and complexes ${ }^{19,20}$ and in the same time thiosemicarbazones exist in equilibrium of various tautomers or conformers which greatly affects their chelating ability ${ }^{21,22}$. On the other hand Nickel can take up different coordination environments (such as octahedral, square-planar and tetrahedral). These special features represent a real challenge to explore the coordination mode of the present complex further.

Till now, no experimental and theoretical data on the main geometric and structural characteristics of $\mathrm{Ni}(\mathrm{CMTSC})_{2}$, which are necessary for a deep understanding of their chemical and physical behavior, have been reported. In this perspective, we report here synthesis, single X-ray structure of [Ni(CMTSC $\left.)_{2}\right]$ DMSO and DFT calculations of both ligand and complex (scheme 1). They were fully optimised with respect to the energy using B3LYP/6$311 \mathrm{G}(\mathrm{d}, \mathrm{p})$ level. 


\section{Experimental and theoretical methods:}

\section{Synthesis}

The complex was obtained in the same way as previously described ${ }^{23}$. It was prepared by the addition of $\mathrm{Ni}(\mathrm{OAc})_{2} 4 \mathrm{H}_{2} \mathrm{O}(0.249 \mathrm{~g}, 1 \mathrm{mmol})$ in absolute EtOH to a hot absolute EtOH solution of the ligand $(0.371 \mathrm{~g}, 2 \mathrm{mmol})$. The mixture was heated under reflux with stirring for $1 \mathrm{~h}$. The precipitate was filtered off hot, washed successively with $\mathrm{EtOH}$ and dried in a vacuum desiccator over silica gel. Additional details will be reported in further report.

\section{X-ray Crystallography and Data Collection.}

Crystals suitable for an X-ray structure determination were obtained by slowly evaporating a DMSO solution of the compound in air at room temperature. X-ray data were recorded on a BrukerAPEX2 diffractometer using Mo K $\alpha$ radiation
(0.71073 A). Data collection and reduction were performed using SAINT softwares ${ }^{24}$. The structure was solved bySIR97 ${ }^{25}$, and refined by SHELXL97 ${ }^{26}$. ORTEP-3 for Windows ${ }^{27}$ and MERCURY ${ }^{28}$ were used for molecular graphics. To prepare material for publication, we used WinGX publication routines ${ }^{29}$.

All non-hydrogen atoms were subjected to anisotropic refinement by full-matrix least squares on $\mathrm{F}^{2}$. The hydrogen atom positions were fixed geometrically at calculated distances and allowed to ride on the parent atoms, except hydrogen atoms bonded to C51, C61, C71, C52, C62, and C72 which were located in a difference Fourier map and refined independently.

A summary of the crystal data, experimental details and refinement results are listed in Table 1. Selected bond lengths and angles are in Table 2, torsion angles in Table 3 and the relevant hydrogen bond parameters are provided in Table 4 .

Table 1. Crystal data, data collection and structure-refinement parameters for [Ni(CMTSC)2] DMSO

\begin{tabular}{|c|c|}
\hline Formula & $\mathrm{C}_{22} \mathrm{H}_{26} \mathrm{~N}_{6} \mathrm{NiOS}_{3}$ \\
\hline Color & Brown \\
\hline Wavelength $(\AA)$ & 0.71073 \\
\hline$T(\mathrm{~K})$ & 293(2) \\
\hline Crystal size (mm) & $0.3 \times \cdot 0.2 \times \cdot 0.2$ \\
\hline Crystal system & Triclinic \\
\hline Space group & $\mathrm{P}-1$ \\
\hline$a(\AA)$ & $8.1750(5)$ \\
\hline$b(\AA)$ & $11.3400(4)$ \\
\hline$c(\AA)$ & $15.1940(4)$ \\
\hline$\alpha\left(^{\circ}\right)$ & $68.581(3)$ \\
\hline$\beta\left(^{\circ}\right)$ & $78.894(4)$ \\
\hline$\gamma\left({ }^{\circ}\right)$ & $79.265(5)$ \\
\hline $\mathrm{V}\left(\mathrm{A}^{0^{3}}\right)$ & $1276.31(10)$ \\
\hline $\mathrm{Z}$ & 2 \\
\hline D calc. $\left(\mathrm{g} \mathrm{cm}^{-1}\right)$ & 1.403 \\
\hline$F w$ & 539.33 \\
\hline Absorption coefficient. $\left(\mathrm{mm}^{-1}\right)$ & 1.031 \\
\hline$F\left(\begin{array}{lll}0 & 0 & 0\end{array}\right)$ & 556 \\
\hline Index ranges & $\begin{array}{l}0 \leq h \leq 5 \\
-14 \leq k \leq 15 \\
-19 \leq l \leq 20\end{array}$ \\
\hline$\theta$ range $\left(^{\circ}\right)$ & $1.45-28.31$ \\
\hline Number of data measured & 3979 \\
\hline Number of data with $\mathrm{I}>2 \sigma(\mathrm{I})$ & 3053 \\
\hline Number of variables & 296 \\
\hline$R_{l}(R l$ all data $)$ & $0.066(0.089)$ \\
\hline$w R_{2}$ & 0.20 \\
\hline $\operatorname{Max} \Delta \mathrm{e} / \AA^{3}$ & 1.070 \\
\hline Max shift & 0.003 \\
\hline Goodness-of-fit on $F^{2}$ & 1.1350 \\
\hline
\end{tabular}




\section{Theoretical and computational details}

A theoretical quantum-chemical method most widely used today is density functional theory (DFT). DFT method combines accuracy with computational speed and ease of use. This is particularly true for hybrid DFT methods, which consistently have been shown to be highly reliable. Of all hybrid DFT methods, the B3LYP functional is the most widely used ${ }^{30}$ and yields accurate results for many systems containing transition metal atoms 31.

For the complex $\mathrm{NiL}_{2}$, initial molecular geometry was taken from crystal structure while initial molecular geometry of ligand HL was taken from crystal structure of similar compound (4-Phenyl-1(3-phenylallylidene) thiosemicarbazide) ${ }^{32}$. Then, Full geometry optimizations were carried out using semiempirical PM3 method $^{33}$ included in hyperchem 8.0.10 ${ }^{34}$. Therefore, DFT $^{35}$ calculations with the B3LYP hybrid functional, in which Becke's three parameter exchange functional ${ }^{36,37}$ and the LeeYang-Parr non-local correlation functional ${ }^{38}$ at basis set 6-311G $(\mathrm{d}, \mathrm{p})^{39}$ were performed with the Gaussian 09 software package $e^{40}$ and Gauss view 5.08 program ${ }^{41}$. The harmonic vibrational frequencies were calculated for the optimized geometries and no imaginary frequencies were found indicating that the optimized structures were stable.

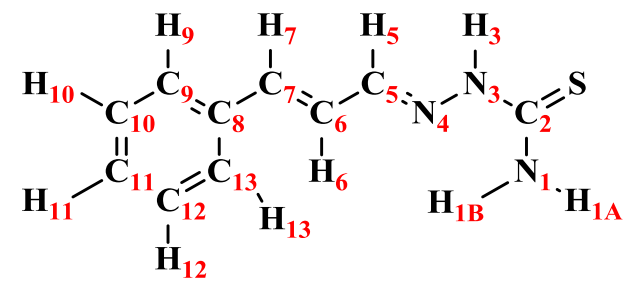

Ligand HL

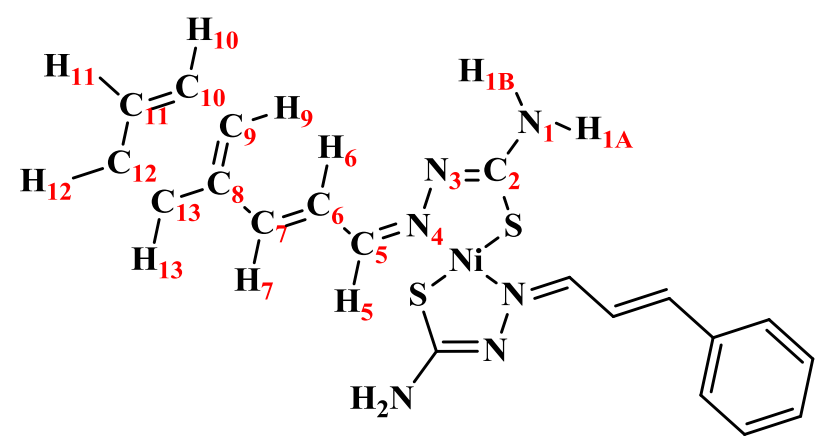

Complex NiL 2

Scheme 1. Chemical structures of the ligand $\mathrm{HL}$ and the complex $\mathrm{NiL}_{2}$ used in this study.

Some electronic properties such as energy of the highest occupied molecular orbital ( $\mathrm{E}_{\text {номо }}$ ), energy of the lowest unoccupied molecular orbital ( $\mathrm{E}_{\mathrm{LUMO}}$ ), energy gap $\left(\mathrm{E}_{\mathrm{GAP}}\right)$ between HOMO and LUMO, dipole moment $(\mu)$, hardness $(\eta)$, Softness $(\sigma)$ and Mulliken charges of all studied compounds were also obtained from the DFT calculations. These quantum chemical parameters $(\eta, \sigma)$ were calculated using the following equations:

$\eta=1 / 2(\mathrm{I}-\mathrm{A})$

$$
\sigma=1 / \eta
$$

where I and A are the ionization potential and electron affinity of the molecule, respectively. According to Koopman's theorem ${ }^{35,42-44}$ using the frontier orbital energies, I and A are given as follows:
$I=-E_{\text {HOMO }}$ and $A=-E_{\text {LUMO }}$

hence,

$\eta=-1 / 2\left(E_{\text {HOMO }}-E_{\text {LUMO }}\right)=-E_{\text {GAP }} / 2$

where $E_{G A P}$ is the HOMO-LUMO energy gap.

\section{Results and discussion:}

\section{Structural description}

A perspective view of the title compound with the atomic numbering scheme is shown in Figure 1. The selected bond distances and angles are listed in Table 2 and Table 3. Selected torsion angles are reported in Table 4. Hydrogen bonding interactions are listed in Table 5. 


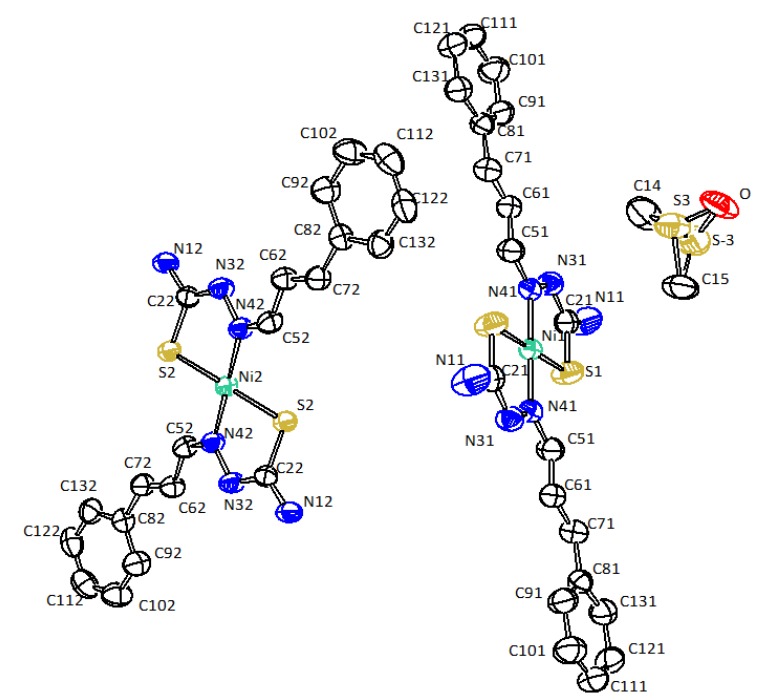

Figure 1. ORTEP drawing with the numbering scheme of the non-hydrogen atoms. Displacement ellipsoids are drawn at the $50 \%$ probability level.

Table 2: Selected bond lengths $(\AA)$ for $\left[\mathrm{Ni}(\mathrm{CMTSC})_{2}\right]$ DMSO

\begin{tabular}{llll}
\hline $\mathrm{Ni}(1)-\mathrm{S}(1)$ & $2.162(2)$ & $\mathrm{Ni}(2)-\mathrm{S}(2)$ & $2.171(1)$ \\
$\mathrm{Ni}(1)-\mathrm{N}(41)$ & $1.932(4)$ & $\mathrm{Ni}(2)-\mathrm{N}(42)$ & $1.914(5)$ \\
$\mathrm{S}(1)-\mathrm{C}(21)$ & $1.722(5)$ & $\mathrm{S}(2)-\mathrm{C}(22)$ & $1.737(5)$ \\
$\mathrm{N}(11)-\mathrm{C}(21)$ & $1.333(7)$ & $\mathrm{N}(12)-\mathrm{C}(22)$ & $1.345(5)$ \\
$\mathrm{N}(31)-\mathrm{C}(21)$ & $1.310(7)$ & $\mathrm{N}(32)-\mathrm{C}(22)$ & $1.302(6)$ \\
$\mathrm{N}(31)-\mathrm{N}(41)$ & $1.387(6)$ & $\mathrm{N}(32)-\mathrm{N}(42)$ & $1.403(5)$ \\
$\mathrm{N}(41)-\mathrm{C}(51)$ & $1.301(6)$ & $\mathrm{N}(42)-\mathrm{C}(52)$ & $1.312(7)$ \\
$\mathrm{C}(61)-\mathrm{C}(51)$ & $1.427(6)$ & $\mathrm{C}(62)-\mathrm{C}(52)$ & $1.432(7)$ \\
$\mathrm{C}(71)-\mathrm{C}(61)$ & $1.342(7)$ & $\mathrm{C}(62)-\mathrm{C}(72)$ & $1.332(7)$ \\
$\mathrm{C}(81)-\mathrm{C}(71)$ & $1.447(6)$ & $\mathrm{C}(72)-\mathrm{C}(82)$ & $1.455(7)$ \\
\hline
\end{tabular}

Table 3: Selected angles $\left({ }^{\circ}\right)$ for $\left[\mathrm{Ni}(\mathrm{CMTSC})_{2}\right]$ DMSO

\begin{tabular}{llll}
\hline $\mathrm{S}(1)-\mathrm{Ni}(1)-\mathrm{N}(41)$ & $94.1(2)$ & $\mathrm{S}(2)-\mathrm{Ni}(2)-\mathrm{N}(42)$ & $94.6(2)$ \\
$\mathrm{Ni}(1)-\mathrm{S}(1)-\mathrm{C}(21)$ & $96.9(2)$ & $\mathrm{Ni}(2)-\mathrm{S}(2)-\mathrm{C}(22)$ & $95.8(2)$ \\
$\mathrm{Ni}(1)-\mathrm{N}(41)-\mathrm{C}(51)$ & $126.7(3)$ & $\mathrm{Ni}(2)-\mathrm{N}(42)-\mathrm{C}(52)$ & $125.4(3)$ \\
$\mathrm{S}(1)-\mathrm{C}(21)-\mathrm{N}(31)$ & $123.3(4)$ & $\mathrm{S}(2)-\mathrm{C}(22)-\mathrm{N}(32)$ & $123.1(3)$ \\
$\mathrm{S}(1)-\mathrm{C}(21)-\mathrm{N}(11)$ & $118.0(4)$ & $\mathrm{S}(2)-\mathrm{C}(22)-\mathrm{N}(12)$ & $117.1(4)$ \\
$\mathrm{Ni}(1)-\mathrm{N}(41)-\mathrm{N}(31)$ & $121.1(3)$ & $\mathrm{Ni}(2)-\mathrm{N}(42)-\mathrm{N}(32)$ & $120.5(2)$ \\
$\mathrm{N}(31)-\mathrm{N}(41)-\mathrm{C}(51)$ & $112.1(4)$ & $\mathrm{Ni}(2)-\mathrm{N}(42)-\mathrm{C}(52)$ & $125.4(3)$ \\
$\mathrm{N}(41)-\mathrm{C}(51)-\mathrm{C}(61)$ & $127.3(5)$ & $\mathrm{N}(42)-\mathrm{C}(52)-\mathrm{C}(62)$ & $128.5(4)$ \\
\hline
\end{tabular}

Table 4: Selected (of) torsion angles $\left(^{\circ}\right)$ for $\left[\mathrm{Ni}(\mathrm{CMTSC})_{2}\right] \mathrm{DMSO}$

\begin{tabular}{llll}
\hline $\mathrm{N}(41)-\mathrm{Ni}(1)-\mathrm{S}(1)-\mathrm{C}(21)$ & $-2.3(2)$ & $\mathrm{N}(42)-\mathrm{Ni}(2)-\mathrm{S}(2)-\mathrm{C}(22)$ & $13.49(17)$ \\
$\mathrm{S}(1)-\mathrm{Ni}(1)-\mathrm{N}(41)-\mathrm{C}(51)$ & $178.9(4)$ & $\mathrm{S}(2)-\mathrm{Ni}(2)-\mathrm{N}(42)-\mathrm{C}(52)$ & $15.5(3)$ \\
$\mathrm{S}(1)-\mathrm{Ni}(1)-\mathrm{N}(41)-\mathrm{N}(31)$ & $1.1(3)$ & $\mathrm{S}(2)-\mathrm{Ni}(2)-\mathrm{N}(42)-\mathrm{N}(32)$ & $-162.2(3)$ \\
$\mathrm{Ni}(2)-\mathrm{S}(2)-\mathrm{C}(22)-\mathrm{N}(12)$ & $169.3(3)$ & $\mathrm{Ni}(1)-\mathrm{S}(1)-\mathrm{C}(21)-\mathrm{N}(11)$ & $-177.2(4)$ \\
\hline
\end{tabular}


Table 5. Selected hydrogen bonding interactions for [Ni(CMTSC $\left.)_{2}\right]$ DMSO

\begin{tabular}{|c|c|c|c|c|}
\hline D-H $\cdots A A$ & $d(\mathrm{D}-\mathrm{H})(\AA)$ & $d(\mathbf{H} \cdots \cdot \mathbf{A})(\stackrel{\AA}{\mathbf{A}})$ & $d(\mathrm{D} \cdots \mathrm{A})(\AA)$ & $\angle$ (DHA) $\left(^{\circ}\right)$ \\
\hline N12-H12A…O \#1 & 0.86 & 2.121 & 2.930 & 156.55 \\
\hline N12-H12B …O \#2 & 0.86 & 2.134 & 2.902 & 148.50 \\
\hline N11-H11B …S2 \#3 & 0.860 & 2.768 & 3.461 & 138.71 \\
\hline C51 -H51…S 1 \# 4 & 0.937 & 2.460 & 3.073 & 123.50 \\
\hline
\end{tabular}

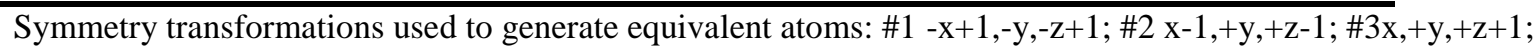
$\# 4-\mathrm{x}+1,-\mathrm{y}+1,-\mathrm{z}+1$

Asymmetric unit includes two semi-molecules (1 and 2) and one DMSO solvent molecule. Both $\mathrm{Ni}$ (II) ions are situated on special positions which leads to two different molecules Ni(CMTSC) 2 . In both molecules, the equivalent anionic CMTSC ligands coordinate to the central metal atom in a bidentate manner via the azomethine nitrogen $\mathrm{N} 41(\mathrm{~N} 42)$ and the thiolato sulfur atoms S1(S2), in square-planar geometry (figure1) forming five membered chelate rings. The sulfur atoms S1(S2) and nitrogen atoms N41(N42) of the two ligands are in a trans-configuration.

The molecules themselves are very close to planar, as shown by the dihedral angles of 4.0 (3) and 6.3 (2) between the two end groups for molecules 1 and 2, respectively.

The negative charge of the deprotonated ligand of the nickel complex is delocalized over the thiosemicarbazone moiety and the $\mathrm{C}-\mathrm{S}$ bond distances are consistent with the increased single bond character, while the imine $\mathrm{C}-\mathrm{N}$ distances and both thioamide $\mathrm{C}-\mathrm{N}$ distances indicate considerable double bond character. This is explained by the difference noted in the level of the bond distances in the deprotonated ligand of the nickel complex which is for $\mathrm{S} 1-\mathrm{C} 21: 1.722(5) \AA(\mathrm{S} 2-\mathrm{C} 22=1.737(5) \AA)$; $\mathrm{C} 21-\mathrm{N} 31=1.310(7) \AA \quad(\mathrm{C} 22-\mathrm{N} 32=1.302(6) \AA)$ (thiolato form) and the bond distances in the case of similar non-deprotonated free ligand, for S-C1 $=1.690(2) \AA, \mathrm{C} 1-\mathrm{N} 2=1.338(2) \AA$ (thione form $)^{45}$.

$\mathrm{Ni}-\mathrm{N}$ and $\mathrm{Ni}-\mathrm{S}$ bond distance are similar to those found in other square-planar nickel thiosemicarbazone complexes ${ }^{23,46}$. Although having similar geometries, the main molecules have significant differences in geometrical parameters around $\mathrm{Ni}(\mathrm{II})$ ions (see torsion angles Table 4). Whereas Ni1 ion is located in a perfect square plane environment $( \pm 0.028 \AA), \mathrm{Ni} 2$ is in a distorted square plane environment $( \pm 1.308 \AA)$. This can be explained by the presence of solvent molecule (DMSO) implicated in Hydrogen bonds with molecule 2 and causing a puckering effect (see Figure 2, Figure 3 and Table 4).

DMSO molecule presents a high thermal agitation on sulfur atom (S3). This latter was set on two different positions with different multiplicities (see deposit).

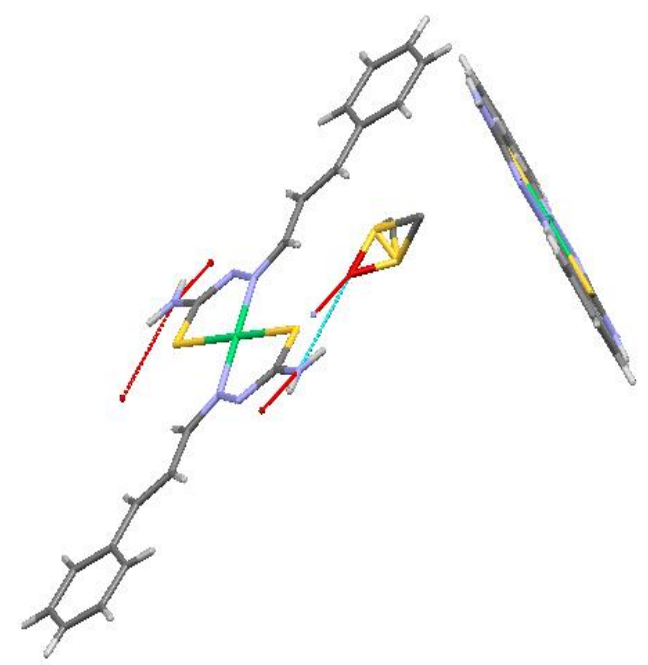

Figure 2. Figure showing molecule 2 implicated in H-bonds. 


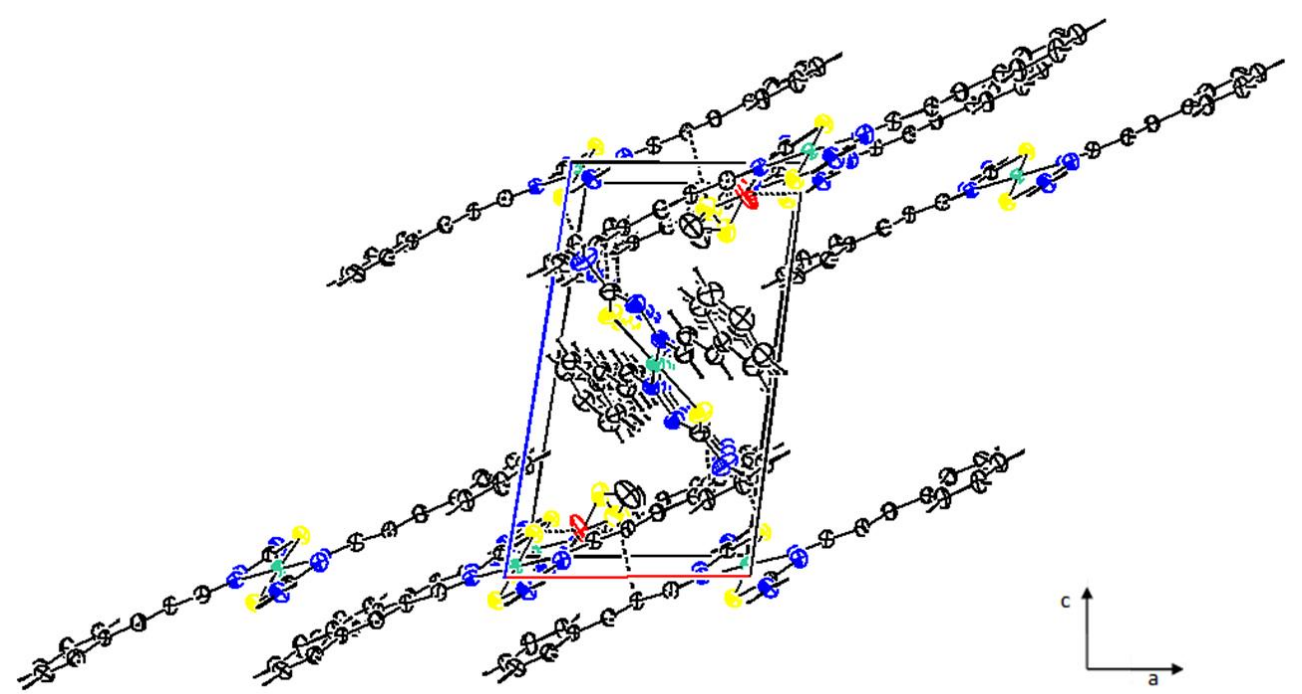

Figure 3. Packing arrangement of the title compound where molecules are packed to form infinite layers parallel along $\mathrm{b}$ axis.

\section{Theoretical results}

Geometric structures

For the two compounds, geometry optimizations shown in Fig. 4 have been performed at B3LYP/6$311 \mathrm{G}(\mathrm{d}, \mathrm{p})$ level of theory and the calculated results are also listed in Table 6 . Thus, the comparisons between the experiments and the calculations can be more straightforward.

As seen in Table 6, for the two compounds, most of the predicted geometric parameters have higher values than those determined experimentally. This is most likely due to the fact that the experimental data describe the compounds in the solid state, whereas the calculated data correspond to the molecules in the gas phase. For the ligand HL, comparing the predicted values with the experimental ones, it can be found that the biggest difference in bond length occurs at bond $\mathrm{C}(6)-\mathrm{C}(7)$ with the difference being $0.0213 \AA$. Considering the bond angles, the biggest variation between the experimental and predicted values can be found at bond angle $\mathrm{C}(5)-\mathrm{N}(4)-\mathrm{N}(3)$ with the difference being $1.60^{\circ}$. For the complex $\mathrm{NiL}_{2}$, the biggest differences of bond length and bond angle between the experiments and calculations are at the $\mathrm{Ni}(1)-\mathrm{S}(1)$ and $\mathrm{N}(31)-\mathrm{N}(41)-\mathrm{C}(51)$, respectively, with the values being $0.053 \AA$ and $3.46^{\circ}$. Since in the calculations, no intermolecular interactions are considered, which results in the theoretical molecules being more spreading themselves and having longer bond lengths and bigger bond angles. In addition, comparing all the parameters of the free ligand $\mathrm{HL}$ and the coordinated $\mathrm{L}^{-}$ion in complex $\mathrm{NiL}_{2}$, there are also some differences between them since the $\mathrm{L}^{-}$is coordinated with $\mathrm{Ni}$ (II) ion (see Table 1). Aforementioned comparisons indicate that, although there exist some differences on the geometrical parameters between the experiments and the predictions, the optimized geometries of the ligand $\mathrm{HL}$ and complex $\mathrm{NiL}_{2}$ resemble closely to their crystal structures and B3LYP/6-311G(d,p) level of theory can provide satisfying calculational precision for the system studied here.

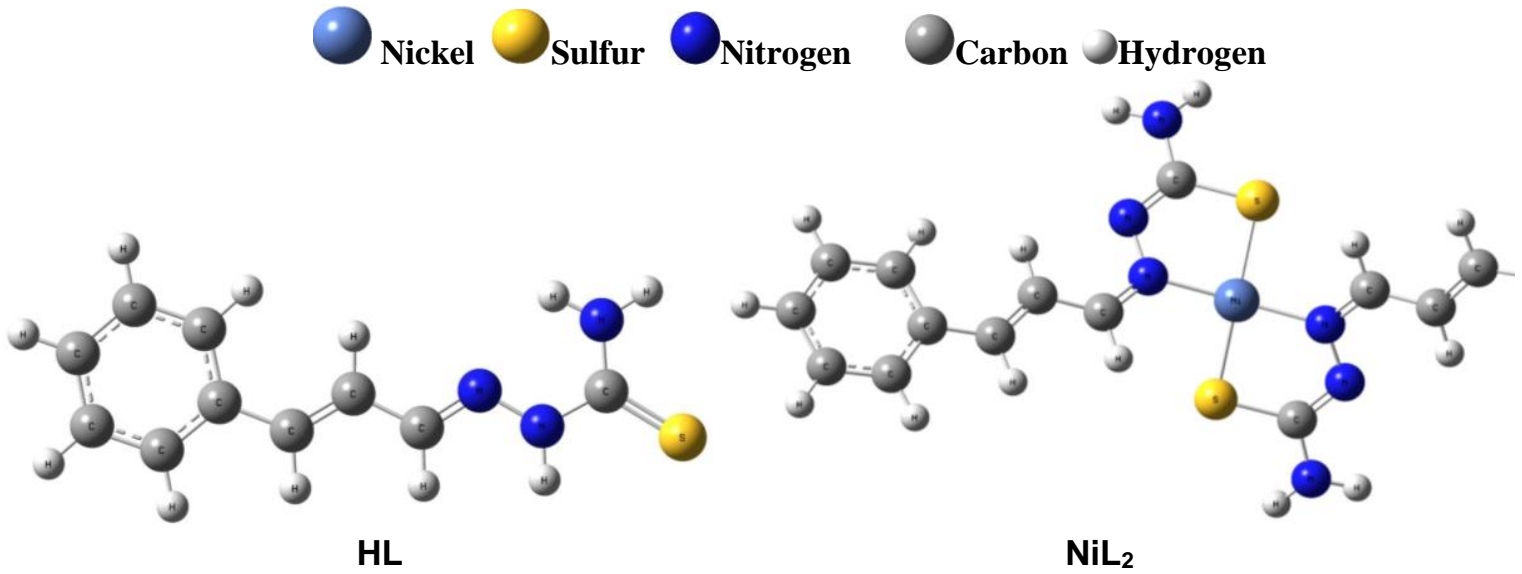

Figure 4. B3LYP/6-311G(d,p) optimized geometry of ligand HL and complex NiL2. 
Table 6. Selected geometric parameters by X-ray and theoretical calculations at B3LYP/6-311(d,p) level of theory for the ligand HL and complex $\mathrm{NiL}_{2}$.

\begin{tabular}{|c|c|c|c|c|c|c|}
\hline \multicolumn{2}{|c|}{ Compound } & \multicolumn{3}{|c|}{ Bond length $(\AA)$} & \multicolumn{2}{|c|}{ Bond angle $\left({ }^{\circ}\right)$} \\
\hline & & Exp. & Calc. & & Exp. & Calc. \\
\hline \multirow[t]{8}{*}{$\mathrm{HL}$} & $\mathrm{C} 2-\mathrm{S}$ & $1.670(1)$ & 1.6787 & N1-C2-N3 & $114.4(2)$ & 114.96 \\
\hline & N4-N3 & $1.369(2)$ & 1.3524 & C2-N3-N4 & $120.2(2)$ & 121.72 \\
\hline & $\mathrm{C} 2-\mathrm{N} 3$ & $1.354(2)$ & 1.3724 & C5-N4-N3 & 116.1(6) & 117.70 \\
\hline & $\mathrm{C} 2-\mathrm{N} 1$ & $1.340(2)$ & 1.3431 & N4-C5-C6 & $121.7(4)$ & 120.95 \\
\hline & C5-N4 & $1.278(2)$ & 1.2894 & C5-C6-C7 & $123.9(2)$ & 122.73 \\
\hline & C5-C6 & $1.423(3)$ & 1.4386 & C6-C7-C8 & $128.2(2)$ & 127.61 \\
\hline & C6-C7 & $1.328(3)$ & 1.3493 & & & \\
\hline & $\mathrm{C} 7-\mathrm{C} 8$ & $1.455(3)$ & 1.4605 & & & \\
\hline \multirow[t]{11}{*}{ NiL2 } & $\mathrm{Ni}(1)-\mathrm{S}(1)$ & $2.162(2)$ & 2.2156 & $\mathrm{~S}(1)-\mathrm{Ni}(1)-\mathrm{N}(41)$ & $94.6(2)$ & 94.93 \\
\hline & $\mathrm{Ni}(1)-\mathrm{N}(41)$ & $1.932(4)$ & 1.9147 & $\mathrm{Ni}(1)-\mathrm{N}(41)-\mathrm{C}(51)$ & $126.7(3)$ & 123.33 \\
\hline & $S(1)-C(21)$ & $1.722(5)$ & 1.7513 & $\mathrm{C}(71)-\mathrm{C}(61)-\mathrm{C}(51)$ & $120.4(4)$ & 120.99 \\
\hline & $\mathrm{N}(11)-\mathrm{C}(21)$ & $1.334(7)$ & 1.3618 & $\mathrm{C}(81)-\mathrm{C}(71)-\mathrm{C}(61)$ & $128.7(5)$ & 127.35 \\
\hline & $\mathrm{N}(41)-\mathrm{C}(51)$ & $1.301(6)$ & 1.3068 & $\mathrm{~N}(41)-\mathrm{C}(51)-\mathrm{C}(61)$ & $127.3(5)$ & 125.92 \\
\hline & $\mathrm{C}(81)-\mathrm{C}(71)$ & $1.447(6)$ & 1.4589 & $\mathrm{~S}(1)-\mathrm{C}(21)-\mathrm{N}(11)$ & $118.0(4)$ & 118.07 \\
\hline & $\mathrm{N}(31)-\mathrm{C}(21)$ & $1.310(6)$ & 1.3044 & $\mathrm{~S}(1)-\mathrm{C}(21)-\mathrm{N}(31)$ & $123.3(4)$ & 123.81 \\
\hline & $\mathrm{C}(61)-\mathrm{C}(71)$ & $1.342(7)$ & 1.3519 & $\mathrm{~N}(11)-\mathrm{C}(21)-\mathrm{N}(31)$ & $118.6(4)$ & 118.06 \\
\hline & $\mathrm{C}(61)-\mathrm{C}(51)$ & $1.427(6)$ & 1.4351 & $\mathrm{~N}(41)-\mathrm{N}(31)-\mathrm{C}(21)$ & $112.6(3)$ & 113.22 \\
\hline & $\mathrm{N}(41)-\mathrm{N}(31)$ & $1.387(4)$ & 1.3764 & $\mathrm{Ni}(1)-\mathrm{N}(41)-\mathrm{N}(31)$ & 121.1(3) & 120.96 \\
\hline & & & & $\mathrm{N}(31)-\mathrm{N}(41)-\mathrm{C}(51)$ & $112.1(4)$ & 115.56 \\
\hline
\end{tabular}

HOMO-LUMO energy gap and related molecular properties

Electron distributions in the frontier molecular orbitals (the highest occupied molecular orbital (HOMO) and the lowest unoccupied molecular orbital (LUMO)) of ligand and Ni (II) complex were calculated and shown in Fig. 5 and Fig. 6 respectively. While the corresponding orbital

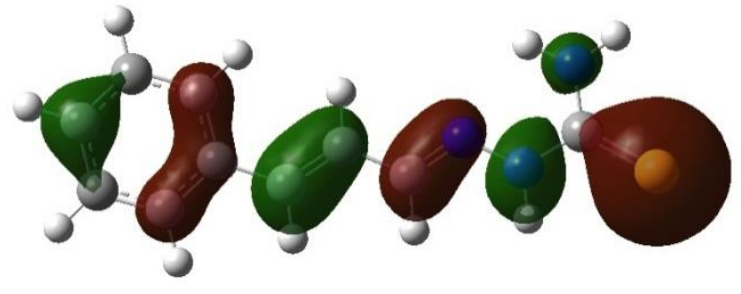

HOMO energy, energy gap, hardness, softness and dipole moment values are presented in Table 7.

As seen in Fig. 5 the HOMO is mainly localized on double bonds, whereas LUMO is generally localized on simple bonds. For the complex (Fig. 6), the HOMO is mainly located around the Ni atom, and the LUMO is localized along the ligand.

Fig. 5. Calculated HOMO and LUMO molecular orbitals of the studied Ligand HL using the B3LYP/6$311 \mathrm{G}(\mathrm{d}, \mathrm{p})$ method
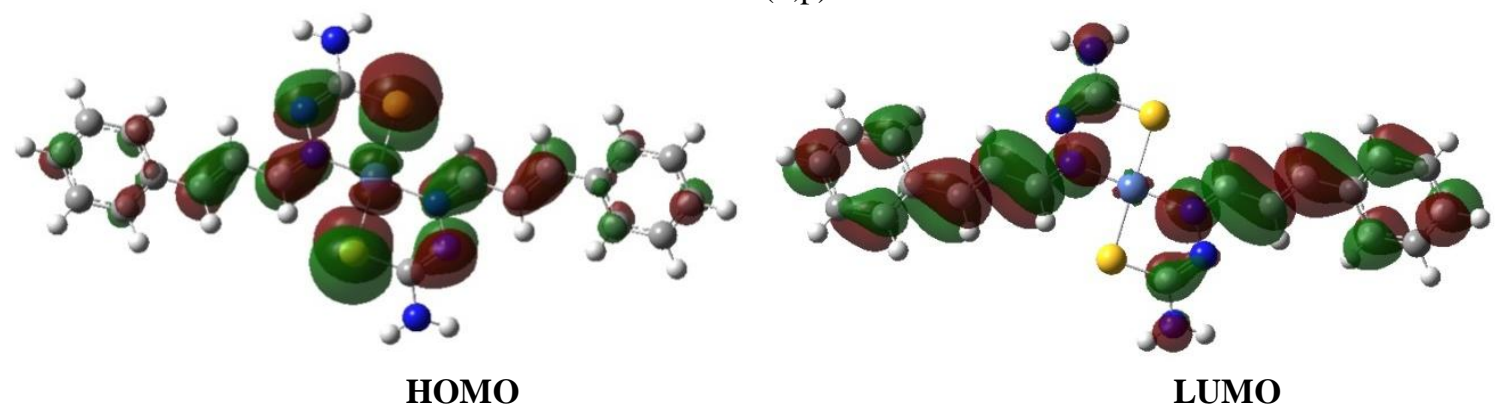

Figure 6. Calculated HOMO and LUMO molecular orbitals of the studied complex $\mathrm{NiL}_{2}$ using the B3LYP/6$311 \mathrm{G}(\mathrm{d}, \mathrm{p})$ method 
Table 7. Calculated HOMO and LUMO energies, HOMO-LUMO gap energies, hardness $(\eta)$ in $\mathrm{eV}$, softness $(\sigma)$ in $\mathrm{eV}^{-1}$ and dipole moment $(\mu)$ values in Debye.

\begin{tabular}{lllllll}
\hline Compounds & HOMO & LUMO & $\boldsymbol{E}_{\boldsymbol{G A P}}$ & $\eta$ & $\sigma$ & $\boldsymbol{\mu}$ \\
\hline $\mathrm{HL}$ & -5.7658 & -2.2751 & 3.4907 & 1.7453 & 0.5729 & 6.1398 \\
$\mathrm{NiL}_{2}$ & -5.2425 & -2.2841 & 2.9584 & 1.4792 & 0.6760 & 0.3983 \\
\hline
\end{tabular}

The energy of HOMO is often associated with the electron-donating ability of a molecule; such that high energy values of HOMO are likely to indicate a tendency of the molecule to donate electrons. The energy of LUMO is related to the electron affinity. The binding ability of the ligand to the metal increases with increasing HOMO energy values ${ }^{47,48}$. The calculations show that HL ligand has the highest HOMO level at $-5.7658 \mathrm{eV}$ and the lowest LUMO level at-2.2751 eV when compared to the obtained parameters for the $\mathrm{NiH}_{2}$ complex.

It has been revealed that the HOMO-LUMO energy gap is an important stability index ${ }^{49,50}$. A large energy gap indicates high stability for the molecule in the chemical reaction. The energy gap for the complex is lower than that of the ligand. This result is consistent with the similar complexes ${ }^{51}$.

The effect of the molecular structure on the chemical reactivity has been object of great interest in several disciplines of chemistry. The hardness and softness are other important parameters, there are commonly used as a criterion of chemical reactivity and stability.

The hardness $(\eta)$ and softness $(\sigma)$ can be estimated from the calculated HOMO and LUMO energies using Equations (1)-(4) $35,52-54$

The smaller values of hardness imply higher reactivity, which means that a molecule with a small HOMO-LUMO gap is more reactive and is a softer molecule. The soft molecules undergo changes in electron density more easily and are more reactive than hard molecules. The hardness value for complex is lower than the ligand and hence its reactivity increases (Table 7 ).

The dipole moment $(\mu)$ is another parameter of the electronic distribution in a molecule which can be related to the dipole-dipole interaction of molecules and metal surface ${ }^{55}$. Ligand with larger dipole moment forms more stable complex ${ }^{56}$. In our case, HL ligand has higher dipole moment than the $\mathrm{NiL}_{2}$ complex (Table 7).

\section{Mulliken atomic charges}

Mulliken atomic charge calculation has an important role in the application of quantum chemical calculation to molecular system because of atomic charges effect dipole moment, molecular polarizability, electronic structure and a lot of properties of molecular systems ${ }^{57}$. The charge distribution over the atoms suggests the formation of donor and acceptor pairs involving the charge transfer in the molecule. Atomic charge has been used to describe the processes of electronegativity equalization and charge transfer in chemical reactions ${ }^{58,59}$. The Mulliken charges of the atoms were calculated for each compounds and shown in Table 8.

Table 8. Mulliken atomic charges calculated by B3LYP/6-311G (d,p) method.

\begin{tabular}{lcc}
\hline Atom & NiL2 & HL \\
\hline Ni & 0.916 & \\
S & -0.348 & -0.264 \\
C2 & 0.174 & 0.199 \\
N3 & -0.264 & -0.265 \\
N4 & -0.434 & -0.210 \\
N1 & -0.412 & -0.426 \\
C5 & 0.167 & 0.106 \\
C6 & -0.129 & -0.123 \\
C7 & -0.056 & -0.062 \\
C8 & -0.078 & -0.073 \\
H1A & 0.243 & 0.263 \\
H1B & 0.223 & 0.240 \\
H5 & 0.142 & 0.252 \\
H6 & 0.119 & 0.082 \\
H7 & 0.098 & 0.101 \\
\hline
\end{tabular}


The Mulliken atomic charges calculated by B3LYP/6-311G (d,p) method are collected in Table 3 . It is worthy to mention that $\mathrm{C} 2$ and $\mathrm{C} 5$ atoms of the ligand and complex exhibit positive charge while C6, C7, C8 atoms exhibit negative charges. The larger negative charge values are found in N1 atom for HL, N4 atom for $\mathrm{NiL}_{2}$ of about -0.426 and -0.434 respectively. The maximum positive atomic is obtained in $\mathrm{C} 2$ atom for $\mathrm{HL}, \mathrm{Ni}$ atom for $\mathrm{NiL}_{2}$. The charge on $\mathrm{H} 1 \mathrm{~A}$ in the $\mathrm{NH}_{2}$ group has the maximum magnitude among the hydrogen atoms present in the title compounds. However all the hydrogen atoms exhibit a net positive charge. The presence of large negative charge on $\mathrm{S}$ and $\mathrm{N}$ atom and net positive charge on $\mathrm{H}$ atoms may suggest the formation of intermolecular interaction in solid forms ${ }^{60}$. This is confirmed by Hydrogen-bonds found in crystalline structure (see Table 5).

\section{Conclusion}

Asymmetric unit includes two semi-molecules and one DMSO solvent molecule. In both molecules, the equivalent anionic CMTSC ligands coordinate to the central metal atom in a bidentate manner via the azomethine nitrogen $\mathrm{N} 4$ and the thiolato sulfur atoms $\mathrm{S}$ in a trans configuration forming a square-planar geometry. Although having similar geometries, the main molecules have significant differences in geometrical parameters around $\mathrm{Ni}(\mathrm{II})$ ions. Whereas $\mathrm{Ni1}$ ion is located in a perfect square plane environment, $\mathrm{Ni} 2$ environment presents some distortions. This can be explained by the presence of solvent molecule (DMSO) implicated in hydrogen bonds with amine group.

The predicted structures of the ligand HL and complex $\mathrm{NiL}_{2}$ at B3LYP/6-311G (d,p) level can well reproduce the structures of the two compounds. Global descriptors, such as ionization energy (I), electron affinity (A), HOMO-LUMO gap, dipole moment $(\mu)$, hardness $(\eta)$ and softness $(\sigma)$ were derived from the DFT calculations and used to identify the differences in the stability and reactivity properties of the studied compounds. Even though, calculations pertain to the gas phase, and the experimental data are for the solid state, in which crystal field effect may affect the relative energies and geometries, Molecular Modeling calculations results hold a good comparison between the theoretically predicted geometries and the experimental ones, which is clearly validating our methodology.

\section{Supporting Information Available}

Crystallographic data for the structural analysis have been deposited at the Cambridge Crystallographic data center, CCDC N¹015255.Copies of this information may be obtained free of charge from the 44(1223)336-033 or Email: deposit@ccdc.cam.ac.uk or www:http://www.ccdc.cam.ac.uk.
Acknowledgments: The authors gratefully acknowledge the support of the Algerian Ministry of Higher Education and Scientific Research.

\section{References}

1- G. Pelosi, F. Bisceglie, F. Bignami, P. Ronzi, P. Schiavone, M.C. Re, C. Casoli, E. Pilotti, J. Med. Chem., 2010, 53, 8765.

2- U. Kulandaivelu, V.G. Padmini, K. Suneetha, B. Shireesha, J.V. Vidyasagar, T.R.Rao, A. Basu, V. Jayaprakash, Arch. Pharm., 2011, 344, 84 .

3- M.D. Hall, K.R. Brimacombe, M.S. Varonka, K.M. Pluchino, J.K. Monda, J. Li, M.J.Walsh, M.B. Boxer, T.H. Warren, H.M. Fales, M.M. Gottesman, J. Med. Chem., 2011, 54, 5878.

4- S. Chandra, S. Bargujar, R. Nirwal, N.Yadav, SpectrochimicaActa. Part A: Molecular and Biomolecular Spectroscopy, 2013, 106, 91-98.

5- M. Jagadeesha, M. Lavanya, S.K. Kalangi, Y. Sarala, C. Ramachandraiah, A. Varada Reddy,SpectrochimicaActa.Part A: Molecular and Biomolecular Spectroscopy, 2015, 135, 180-184.

6- R.L. Arrowsmith, S.I. Pascu, H. Smugowski, Organomet. Chem., 2012, 38, 1-35.

7- Giorgio Pelosi, The Open Crystallography Journal, 2010, 3, 16-28.

8- S. Lhuachan, S. Siripaisarnpipat, N. Chaichat, Eur. J. Inorg. Chem., 2003, 263.

9- D. Kovala-Demertzi, M.A. Demertzis, J.R. Miller, C.S. Prampton, J.P. Jasinski, D.X.West, J. Inorg. Biochem., 2002, 92, 137.

10- P.N. Yadav, M.A. Demertzis, D. KovalaDemertzi, S. Skoulika, D.X. West, Inorg. Chim. Acta., 2003, 349, 30.

11- L.A. Ashfield, A.R. Cowley, J.R. Dilworth, P.S. Donnely, Inorg. Chem., 2004, 43, 4121.

12- I. Paul, F. Basuli, T.C.W. Mak, S. Bhattacharya, Angew. Chem. Int. Ed., 2001, 40, 2923.

13- S.I. Orysyk, V.V. Bon, O.O. Obolentseva, Yu.L. Zborovskii, V.V. Orysyk, V.I.Pekhnyo, V.I. Staninets, V.M. Vovk, Inorg. Chim. Acta., 2012, 382, 127.

14- T.S. Lobana, G. Bhargava, V. Sharma, M. Kumar, Indian J. Chem., Sect. A: Inorg. Bio-inorg., Phys., Theor. Anal. Chem., 2003, 42A, 309.

15- F.H. Allen, Acta Crystallogr. Sect. B, 2002, 58, 380.

16- D. Pandiarajan, R. Ramesh, Inorg. Chem. Commun., 2011, 14, 686.

17- N. SahaChowdhury, D. Kumar Seth, M.G.B. Drew, S. Bhattacharya, Inorg. Chim.Acta., 2011, 372, 183.

18- T.S. Lobana, R. Sharma, G. Bawa, S. Khanna, Coord. Chem. Rev., 2009, 253, 977.

19- D. Maity, A.K. Manna, D. Karthigeyan, T.K. Kundu, S.K. Pati, T. Govindaraju, Chem. Eur. J., 2011, 17, 11152-11161. 
20- R. Santhakumari, K. Ramamurthi, G. Vasuki, B.M. Yamin, G. Bhagavannarayana, Spectrochim. Acta, 2010, 76, 369.

21- V. Ruangpornvisuti, B. Wanno, J. Mol. Mod.,2004,10, 418.

22- S.B. Jiménez-Pulido, F.M. Linares-Ordóñez, M.N. Moreno-Carretero, M. QuirósOlozábal, Inorg. Chem., 2008, 47, 1096.

23- Y. Harek, L. Larabi, L. Boukli, F. Kadri, N. Benali-Cherif, M. M. Mostafa, Transition Metal Chemistry, 2005, 30, 121-127.

24- Bruker, Smart and Saint Bruker AXS, Madison, 2004.

25- A. Altomare, M. C. Burla, M. Camalli, G. L. Cascarano, C. Giacovazzo, A. Guagliardi, A. G. Moliterni, G. Polidori\& R. Spagna, J.Appl. Cryst., 1999, 32, 115-119.

26- G. M. Sheldrick,ActaCryst. A, 2008, 64, 112-122.

27- L. J.Farrugia,J. Appl. Cryst., 1999, 32, 837-838.

28- C. F.Macrae,I. J.Bruno, J. A.Chisholm, P. R.Edgington, P.McCabe, E.Pidcock, L.Rodriguez-Monge, R.Taylor, J.van de Streek and P. A.Wood, J. Appl. Cryst., 2008, 41, 466-470.

29- L. J.Farrugia, J. Appl. Cryst., 2012, 45, 849-854.

30- A.P. Scott, L. Radom, J. Phys. Chem., 1996, 100, 16502-16513.

31- A. Ricca, C.W. Bauschlicher Jr., J. Phys. Chem., 1995, 99, 9003-9007.

32- J. Song, F. Zhu, H. Wang, P. Zhao, Spectrochimica Acta Part A Molecular and Biomolecular Spectroscopy, 2014, 129, 227-234.

33- J.J.P. Stewart, J. Comput. Chem., 1989, 2, 209.

34- HyperChem version 8.0.10 Hypercube Inc, 2011.

35- R.G. Parr, W. Yang, Density Functional Theory of Atoms and Molecules, Oxford University Press, New York 1989.

36- A.D. Becke, Density-functional exchangeenergy approximation with correct asymptotic behavior. Phys. Rev. A., 1988, 38, 3098-3100.

37- A.D. Becke, J. Chem. Phys., 1993, 98, 1372-1377.

38- C. Lee, W. Yang, R.G. Parr, Phys. Rev. B.,1988,37, 785-789.

39- E.V.R. de Castro, F.E. Jorge, Journal of Chemical Physics, 1998, 108, 5225-5229.

40- M.J. Frisch, G.W. Trucks, H.B. Schlegel, G.E. Scuseria, M.A. Robb, J.R. Cheeseman, G. Scalmani, V. Barone, B. Mennucci, G.A. Petersson, H. Nakatsuji, M. Caricato, X. Li, H.P. Hratchian, A.F. Izmaylov, J. Bloino, G. Zheng, J.L. Sonnenberg, M. Hada, M. Ehara, K. Toyota, R. Fukuda, J. Hasegawa, M. Ishida, T. Nakajima, Y. Honda, O. Kitao, H. Nakai, T. Vreven, J.A. Montgomery, Jr, J.E. Peralta, F. Ogliaro, M. Bearpark, J.J. Heyd,
E. Brothers, K.N. Kudin, V.N. Staroverov,

R. Kobayashi, J. Normand, K. Raghavachari, A. Rendell, J.C. Burant, S.S. Iyengar, J. Tomasi, M. Cossi, N. Rega, J.M. Millam, M. Klene, J.E. Knox, J.B. Cross, V. Bakken, C. Adamo, J. Jaramillo, R. Gomperts, R.E. Stratmann, O. Yazyev, A.J. Austin, R. Cammi, C. Pomelli, J.W. Ochterski, R.L. Martin, K. Morokuma, V.G. Zakrzewski, G.A. Voth, P. Salvador, J.J. Dannenberg, S. Dapprich, A.D. Daniels, O. Farkas, J.B. Foresman, J.V. Ortiz, J. Cioslowski, D.J. Fox, Gaussian 09, Revision A.1, Gaussian Inc., Wallingford, CT, 2009.

41- R.D. Dennington II, T.A. Keith, J.M. Millam, GaussView 5.0, Wallingford CT, 2009.

42- R.K Singh, S.K. Verma, P.D. Sharma, Int. J. Chem. Technol. Res., 2011, 3, 1571-1579.

43- C.G. Zhan, J.A. Nichols, D.A. Dixon, J. Phys. Chem. A, 2003, 107, 4184-4195.

44- R.G. Pearson, J. Am. Chem. Soc., 1985, 107, 6801-6806.

45- E. M.Jouad, M.Allain, M. A.Khanand G. M.Bouet,J. Mol. Struct., 2002, 604, 205.

46- Y. M.Chumanov, N.M.Samus, G.Bocelli, Y. K.Suponitski, V. I. Tsapkov,A. P. Gulya,Russian Journal of Coordination Chemistry, 2006, 32, 14-20.

47- S. Sagdinc, B. Koksoy, F. Kandemirli, S.H. Bayari, J. Mol. Struct., 2009, 91, 63-70.

48- A.A.R. Despaigne, J.G. Da Silva, A.C.M. Do Carmo, F. Sives, O.E. Piro, E.E. Castellano, H. Beraldo, Polyhedron, 2009, 28, 3797-3803.

49- Z. Zhou, R.G. Parr, J. Am. Chem. Soc., 1990, 112, 5720-5724.

50- R.G. Pearson, J. Am. Chem. Soc., 1988, 110, 2092-2097.

51- J. Song, F. Zhu, H. Wang, P. Zhao, Spectrochimica Acta Part A Molecular and Biomolecular Spectroscopy, 2014, 129, 227-234.

52- R.K. Singh, S.K. Verma, P.D. Sharma, Int. J. Chem. Technol. Res., 2011, 3, 1571-1579.

53- C.G. Zhan, J.A. Nichols, D.A. Dixon, J. Phys. Chem. A, 2003, 107, 4184-4195.

54- R.G. Pearson, J. Am. Chem. Soc., 1985, 107, 6801-6806.

55- A.O Yüce, B.D Mert, G. Kardas, B. Yazıcı, Corrosion Science, 2014, 83, 310-316.

56- G.B. Saha, Fundamentals of nuclear pharmacy, Springer, 2010, 6 .

57- I. Sidir, Y.G. Sidir, M. Kumalar, E. Tasal, J. Mol. Struct., 2010, 964, 134.

58- K. Jug, Z.B. Maksic, in: Theoretical Model of Chemical Bonding, Ed. Z.B. Maksic, Part 3, Springer, Berlin 1991, p. 29, p. 233.

59- S. Fliszar, Charge Distributions and Chemical Effects, Springer, New York, 1983.

60- L.X. Hong, L.X. Ru, Z.X. Zhou, Comput. Theor. Chem., 2011, 969, 27. 